\title{
Coparentalidade no Contexto de Depressão Pós-Parto: Um Estudo Qualitativo
}

\author{
Giana Bitencourt Frizzo' \\ Beatriz Schmidt \\ Vanessa de Vargas $^{1}$ \\ Cesar Augusto Piccinini ${ }^{1}$
}

${ }^{1}$ Universidade Federal do Rio Grande do Sul, Porto Alegre, RS

\begin{abstract}
Resumo
O objetivo deste estudo foi investigar a coparentalidade no contexto de depressão pós-parto. Participaram 11 famílias com bebês no primeiro ano de vida, em que a mãe apresentava depressão pós-parto. A mãe e o pai responderam entrevista sobre sua experiência de maternidade e paternidade, respectivamente. Essas entrevistas foram examinadas por meio de análise de conteúdo qualitativa, com base em quatro categorias da coparentalidade: divisão de trabalho parental, apoio versus depreciação coparental, gerenciamento das interações familiares e acordo nos cuidados. Os achados evidenciaram que sintomas de depressão pós-parto, como irritabilidade e cansaço, apareceram associados principalmente a relatos de pouco apoio e de depreciação coparental, por parte de ambos os genitores. Os resultados também revelaram certa dificuldade materna para estabelecer interações triádicas, bem como estratégias negativas de resolução de conflitos coparentais. Discutem-se implicações da depressão pós-parto na coparentalidade.

Palavras-chave: coparentalidade, depressão pós-parto, relações familiares, relações pais-criança
\end{abstract}

\section{Coparenting in the Context of Postpartum Depression: A Qualitative Study}

\begin{abstract}
The aim of this study was to investigate coparenting in the context of postpartum depression. The participants were 11 families, with babies in their first year of life, in which the mother showed postpartum depression. The mother and father were interviewed about their experience of maternity and paternity, respectively. These interviews were examined through qualitative content analysis, based on four categories of coparenting: parental division of labor, coparental support versus undermining, joint family management, and childrearing agreement. The results revealed that postpartum depression symptoms, such as irritability and tiredness, appeared mainly associated with reports of low support and coparental undermining by both parents. The results also revealed a certain maternal difficulty to establish triadic interactions, as well as negative strategies for coparental conflict resolution. Implications of postpartum depression in coparenting are discussed.
\end{abstract}

Keywords: coparenting; postpartum depression; family relations; parent child relations

\section{Coparentalidad en el Contexto de Depresión Postparto: Un Estudio Cualitativo}

\begin{abstract}
Resumen
El objeto de este estudio fue investigar la coparentalidad en el contexto de depresión posparto. Participaron 11 familias con bebes en el primer año de vida, en que la madre presentaba depresión posparto. La madre y el padre respondieron a una entrevista sobre su experiencia de maternidad y paternidad, respectivamente. Estas entrevistas fueron examinadas por medio de análisis de contenido cualitativo, con base en cuatro categorías de la coparentalidad: división de trabajo parental, apoyo versus depreciación coparental, gerenciamiento de las interacciones familiares, y acuerdo en los cuidados. Los hallazgos evidenciaron que los síntomas de depresión posparto, como irritabilidad y cansancio, aparecieron asociados principalmente a relatos de poco apoyo y de depreciación coparental, por parte de ambos padres. Los resultados también revelaron cierta dificultad materna para establecer interacciones triádicas, así como estrategias negativas de resolución de conflictos coparentales. Se discuten implicaciones de la depresión posparto en la coparentalidad.

Palabras-clave: coparentalidad; depresión posparto; relaciones familiares; relaciones padres-niño
\end{abstract}

A coparentalidade se refere à maneira como os genitores ${ }^{1}$ ou as figuras parentais coordenam e se apoiam no processo de cuidar dos filhos, consistindo na responsabilidade compartilhada no papel de cuidadores (Feinberg, 2003). Contudo, não implica que as

\footnotetext{
1 No presente estudo, o termo "genitores" será utilizado para designar mãe e pai, conjuntamente. O termo "pais" será utilizado para se referir apenas aos homens.
}

tarefas de cuidado sejam igualmente distribuídas entre os genitores, visto que uma relação coparental efetiva e satisfatória pode assumir diferentes arranjos em cada família (Schoppe-Sullivan \& Mangelsdorf, 2013). O modelo de coparentalidade proposto por Feinberg (2003) é composto por quatro dimensões: (1) divisão de trabalho parental, que se refere à forma como os cuidados são divididos e à satisfação com essa divisão; 
(2) apoio versus depreciação coparental, que envolve cooperatividade ou hostilidade entre os genitores; (3) gerenciamento das interações familiares, que diz respeito ao controle dos genitores sobre o modo como se comunicam e interagem nas relações familiares; e (4) acordo nos cuidados, envolvendo necessidades emocionais, expectativas de comportamento, disciplina e prioridades educacionais para o filho.

Diversos estudos têm sugerido que a coparentalidade se associa ao bem-estar e ao desenvolvimento dos membros da família (Cabrera, Shannon, \& Taillade, 2009; Don, Biehle, \& Mickelson, 2013; Maršanić \& Kušmić, 2013; Schmidt, Arenhart, Lopes, \& Piccinini, 2017; Van Egeren, 2004). Conforme McDaniel (2016), a maior parte dos estudos sobre coparentalidade remonta à teoria dos sistemas familiares, cujo principal expoente é Minuchin (1982). Com base nessa teoria, a família se caracteriza como um sistema aberto em constante transformação, que enfrenta uma série de tarefas desenvolvimentais e necessita, continuamente, adaptar-se e se reestruturar. Segundo Cowan e Cowan (2016), dentre as transições normativas do ciclo de vida da família, a mais significativa e estressante é a transição para a parentalidade, em particular quando o filho é primogênito. Isso porque os novos genitores devem reorganizar seus padrões de comportamento e seus respectivos papéis, no sentido de abrir espaço ao bebê no sistema familiar, atendendo às necessidades dele (Block, 2016; Goldberg \& Perry-Jenkins, 2004).

Sem dúvida, a transição para a parentalidade é um momento complexo notadamente para a mãe, pois além de gestar o filho, ela costuma ser a principal responsável pelos cuidados ao bebê (McClain \& Brown, 2016; Piccinini, Silva, Gonçalves, Lopes, \& Tudge, 2012), mesmo nas famílias em que ambos os genitores têm emprego (Martins, Leal, Schmidt, \& Piccinini, 2016; Schoppe-Sullivan et al., 2016). Isso está associado tanto às demandas da amamentação (Frizzo, Prado, Linares, \& Piccinini, 2010), à maior disponibilidade de tempo, em função da licença-maternidade (Pasinato \& Mosmann, 2016), mas também à tradicional divisão de papéis na família ocidental, em que as mães são as principais cuidadoras dos filhos (Verza, Sattler, \& Strey, 2015).

Nesse sentido, evidências revelam a tendência de vulnerabilização da mulher após o nascimento de um filho (Murray, 2015), bem como o aumento da probabilidade de emergência de problemas de saúde mental (Schoppe-Sullivan et al., 2016), em particular a depressão, que pode acometer à mãe no puerpério (Cooper \&
Murray, 1995; Frizzo et al., 2010). Sintomas de depressão são relativamente comuns na transição para a parentalidade, de modo que, aproximadamente 15\% das mães, preenchem critérios clínicos para transtorno depressivo no primeiro ano após o nascimento de um filho (Tissot, Favez, Frascarolo, \& Despland, 2016). No caso do Brasil, evidências sugerem índices ainda maiores. Por exemplo, em estudo do qual participaram 23.894 mulheres brasileiras com bebês de até 18 meses de idade, em que se aplicou a Escala de Depressão Pós -parto de Edimburgo (EPDS), a prevalência de casos de depressão foi de 26,3\% (Theme Filha, Ayers, Gama, \& Leal, 2016).

Os sintomas de depressão pós-parto frequentemente incluem humor deprimido (triste ou irritadiço), perda de interesse por atividades outrora consideradas prazerosas, alterações no apetite e no sono, cansaço, dificuldade de concentração, sentimentos de inutilidade e culpa, bem como ideação suicida (Sit \& Wisner, 2009). Segundo o Manual Diagnóstico e Estatístico de Transtornos Mentais (DSM-5, 2014), a depressão pós-parto inicia durante a gestação ou em até quatro semanas após o parto; sua avaliação deve levar em conta o diagnóstico diferencial em relação ao quadro de baby blues, o qual é transitório, incluindo sintomas como choro, irritabilidade, reatividade emocional e alterações no sono. Os sintomas de baby blues afetam em torno de $75 \%$ das novas mães, sendo que comumente iniciam nos dois primeiros dias após o parto e cessam espontaneamente em torno do décimo dia após o parto (Sit \& Wisner, 2009).

Além de trazer consequências negativas à mãe, a depressão afeta as relações entre todos os membros da família (Frizzo, Prado, Linares, \& Piccinini, 2011a; Silva, Pizeta, \& Loureiro, 2016; Williams, 2018). Isso ocorre tanto pela seriedade da situação clínica, como pelo fato de que aquilo que acontece a um dos membros da família tende a impactar todos os demais, pois eles interagem e se influenciam mutuamente, como destacado pela teoria sistêmica (McDaniel, 2016; Minuchin, 1982). De tal maneira, diversos estudos têm apontado que a depressão pós-parto pode trazer desdobramentos negativos às relações diádicas, tanto parentais (Piccinini, Frizzo, Brys, \& Lopes, 2014; Schmidt, Piccoloto, \& Müller, 2005) como conjugais (Frizzo, Silva, Piccinini, \& Lopes, 2011b; Sit \& Wisner, 2009). Por exemplo, o fato de o pai não conseguir auxiliar a mãe deprimida a superar os sintomas, tende a ser uma fonte de angústia paterna (Frizzo et al., 2011a). Por outro lado, ao não alcançar as suas expectativas e cumprir as suas supostas 
responsabilidades, a mãe deprimida pode vivenciar sentimento de culpa, o que afeta a relação que ela estabelece com a criança e com o cônjuge.

Assim, também há indicativos de desdobramentos negativos para as relações triádicas, no sentido de que a depressão pode fragilizar a coparentalidade (Don et al., 2013; Favez, Tissot, Frascarolo, Stiefel, \& Despland, 2016; Pinto, 2014; Williams, 2018). O estudo de Favez, Tissot, Frascarolo, Stiefel e Despland, (2016), com 69 tríades mãe-pai-bebê suíços, evidenciou que quanto mais depressão, mais conflito e menos apoio parental. Já os achados de Don et al. (2013), com 84 famílias norte-americanas que tiveram seu primeiro filho, revelaram que a percepção de acordo entre os genitores sobre os cuidados parentais predisse menores níveis de depressão. Por outro lado, altos níveis de discordância entre os genitores tenderiam a asseverar sintomas de depressão e a fragilizar a expressão de afeto positivo na relação coparental.

Além disso, um dos aspectos relativos à coparentalidade que pode afetar a saúde mental das mulheres é a divisão de trabalho parental, em especial no período de transição para a parentalidade (Goldberg \& PerryJenkins, 2004). Conforme essas autoras, a assimetria na distribuição de tarefas e responsabilidades tende a se fazer presente e, mesmo quando ambos os genitores têm emprego, as mulheres assumem grande parte da rotina de cuidados ao bebê e de atividades domésticas, o que pode levar a maiores índices de depressão nas mães.

$\mathrm{Na}$ verdade, não somente em famílias com bebês, mas também em famílias com crianças maiores, há uma tendência de redução de interações familiares positivas e aumento das negativas, quando um dos genitores está com depressão (McDaniel, 2016; Williams, 2018). Nesse contexto, os genitores apresentariam mais dificuldades para se relacionar de modo cooperativo e para tolerar a frustração, o que também se associa à coparentalidade. Além disso, os efeitos potencialmente negativos da depressão sobre as relações coparentais parecem persistentes longitudinalmente, conforme revelado no estudo de Williams (2018), que acompanhou famílias durante os cinco primeiros anos de vida da criança. Os achados desse estudo evidenciaram que sintomas de depressão apresentados por um dos genitores em períodos iniciais se associaram a baixos níveis de apoio coparental em períodos posteriores do desenvolvimento. Portanto, diagnosticar e tratar a depressão precocemente, em particular no período pós-parto, parece ser crucial para a qualidade da coparentalidade ao longo do tempo, visando à prevenção de implicações negativas e à promoção da saúde e do bem-estar familiar.

Nesse sentido, o objetivo do presente estudo foi investigar a coparentalidade no contexto de depressão pós-parto. Face ao exposto na literatura, é esperada uma estreita relação entre a depressão pós-parto e as interações dos membros da família, com implicações para o desenvolvimento individual e para a coparentalidade.

\section{Método}

\section{Participantes}

Participaram desse estudo famílias com bebês, nas quais a mãe apresentava indicadores de depressão com base no Inventário de Depressão Beck (Beck \& Steer, 1993; Cunha, 2001) e em entrevista diagnóstica (GIDEP/NUDIF, 2003). Os bebês (cinco meninas e seis meninos) eram saudáveis e tinham média de idade de 5,4 meses ( $D P=3,2)$, no momento da coleta de dados. Os genitores residiam juntos, em situação matrimonial, na região metropolitana de Porto Alegre. A média de idade das mulheres era de 31,5 anos $(D P=$ $6,7)$ e a dos homens era de 33,1 anos $(D P=6,2)$. O número de filhos das famílias variou de um a quatro $(M=2,0 ; D P=1,1)$, sendo que a mãe era primípara em cinco casos.

O nível educacional dos genitores variou de ensino fundamental a pós-graduação. A média de escolaridade das mulheres era de 11,4 anos (DP = $2,3)$, sendo que a maioria delas havia concluído ensino médio $(n=7)$. A média de escolaridade homens era de 13,2 anos $(D P=3,6)$, sendo que a maioria deles havia concluído ensino médio $(n=6)$. Em sete famílias, ambos os genitores estavam inseridos no mercado de trabalho, ao passo que, em quatro famílias, apenas o pai tinha emprego.

Os participantes integraram o projeto intitulado $O$ impacto da psicoterapia para a depressão materna e para a interação pais-bebê: Estudo longitudinal do nascimento ao segundo ano de vida do bebê - PSICDEMA $A^{2}$ (Piccinini et al., 2003). Para fins do presente estudo, das 23 famílias participantes do PSICDEMA, foram selecionadas apenas aquelas

2 O estudo envolveu quatro fases de coleta de dados. A Fase I, durante o primeiro ano de vida do bebê, contemplou a avaliação e a caracterização dos aspectos psicológicos dos participantes. A Fase II compreendeu a realização da Psicoterapia Breve Pais-bebê, visando melhorar as relações familiares. As Fases III e IV foram realizadas, respectivamente, uma semana e seis meses após a psicoterapia, quando houve uma nova avaliação psicológica dos participantes. 
em que a mãe e o pai coabitavam e haviam respondido a todos os instrumentos aplicados na Fase I de coleta de dados do projeto, antes da realização da psicoterapia, que ocorreu na Fase II, visto que o objetivo era investigar a coparentalidade no contexto de depressão pós-parto. O PSICDEMA foi aprovado por diversos Comitês de Ética (Informação Retirada pela Revista).

\section{Procedimentos e Instrumentos}

O procedimento de coleta de dados seguiu as etapas do PSICDEMA, cujos detalhes se encontram em Piccinini et al. (2003). Dessa forma, serão destacados aqui apenas os procedimentos e os instrumentos que foram utilizados no presente estudo.

Inicialmente, cada família preencheu a Ficha de contato inicial, que visou examinar se os critérios para participar do projeto eram atendidos. Com as famílias selecionadas, realizou-se a coleta de dados em uma sala do Instituto de Psicologia da Universidade (Informação Retirada pela Revista). A mãe e o pai responderam, separadamente, à Entrevista de dados demográficos, ao Inventário de Depressão Beck e à Entrevista diagnóstica, que visava investigar a depressão pós-parto, por meio de uma série de questões sobre: sintomas atuais do pós-parto (sentimentos de culpa/inutilidade, alterações de sono, apetite, capacidade de concentração); humor deprimido (triste ou irritadiço, ideação suicida); história imediata da mãe e do pai na gestação; qualidade de seus relacionamentos (com o bebê, com a família e com a/o cônjuge); e o histórico médico. Além disso, a mãe respondeu à entrevista sobre a experiência da maternidade, que investigava diversos aspectos da experiência de ser mãe, em particular as expectativas, as dificuldades e os sentimentos a respeito da maternidade, e o pai respondeu à entrevista sobre a experiência da paternidade, que era semelhante à da mãe, mas com foco na paternidade. Todas as entrevistas foram gravadas em áudio e transcritas.

\section{Resultados}

Os dados derivados das entrevistas sobre a experiência da maternidade e da paternidade foram analisados por meio de análise de conteúdo qualitativa (Laville \& Dionne, 1999), com base nas quatro categorias componentes do modelo de coparentalidade proposto por Feinberg (2003), já definidas anteriormente: divisão de trabalho parental, apoio versus depreciação coparental, gerenciamento das interações familiares e acordo nos cuidados. Inicialmente, dois autores do presente estudo leram repetidamente a transcrição completa das entrevistas, visando à familiarização com os dados. Em seguida, esses mesmos autores classificaram de forma independente as narrativas de mães e pais nas quatro categorias de análise. Dúvidas e discordâncias foram discutidas, buscando-se consenso.

Cabe destacar que, embora a aplicação dos instrumentos tenha sido realizada separadamente com cada genitor, na análise dos dados se levou em conta a dinâmica relacional da tríade mãe-pai-bebê, considerando as particularidades de cada família (cf. Maršanić \& Kušmić, 2013). Dessa forma, a unidade de análise para a categorização dos relatos foi a família, independente de a fala ter sido expressa por um ou outro genitor, ou por ambos. Isso porque se entende que as percepções de apenas um dos genitores já indicam aspectos importantes da dinâmica relacional da tríade mãe-pai -bebê, visto que os membros da família interagem e se influenciam mutuamente (Minuchin, 1982). A seguir, serão apresentados os resultados para cada categoria, ilustrando-as com relatos dos participantes ${ }^{3}$.

\section{Divisão de Trabalho Parental}

Nessa categoria, foram considerados os relatos de mães e pais sobre a distribuição de tarefas e responsabilidades envolvendo o bebê, bem como a satisfação quanto a essa divisão, no que tange a rotina de cuidados, atividades domésticas e aspectos financeiros. Os relatos revelaram que a rotina de cuidados ao bebê e de atividades domésticas estava predominantemente sob responsabilidade materna, na grande maioria das famílias ${ }^{4}$. Isso foi indicado tanto pelas mães: “ $O$ [pai] não sabe nem que roupa colocar, quantas fraldas vão na mochila do [filho]. Eu peço pra ele: 'Olha a mochila'. Não, isso é coisa tua [da mãe]. Não faço ideia do que o [filho] vai levar" (M8); quanto pelos pais: "Sei que eu tô com um

\footnotetext{
3 A categorização das respostas às entrevistas gerou inúmeros outros exemplos de relatos dos participantes, que não foram incluídos no presente artigo por falta de espaço. Em função disso, aqui também se editou algumas citações, excluindo partes que não eram fundamentais para o seu entendimento, ou acrescentando, entre colchetes, expressões para facilitá-lo. Ademais, a autoria das vinhetas foi identificada pelas letras "M" e "P", referentes à mãe e ao pai, respectivamente, seguidas do número do caso.

4 Para facilitar a exposição dos achados, foi utilizada a seguinte descrição, quanto ao número de participantes que fizeram relatos classificados em cada categoria: uma/algumas famílias: 1 a 3; muitas famílias: 4 a 6; a maioria das famílias: 7 a 9; a grande maioria/todas as famílias: 10 e 11.
} 
ponco de preguiça. Algumas coisas, eu deixei um ponco pra ela. Comidinha é ela que faz, os mamás, água" (P7).

Dentre as razões associadas ao compartilhamento pouco igualitário de tarefas e responsabilidades, na maioria das famílias, identificou-se a crença de que a mãe teria maior aptidão do que o pai para a realização dos cuidados ao bebê, segundo relatos maternos: "Eu acho [o filho] tão indefeso, assim. Ele [pai] não sabe mexer" (M7); e paternos: "Eu participo, mas não sou que nem a mãe. Não pensava que eu ia ter que dar banho, trocar, levar, né? Eu deixo mais pra ela. Eu acho que a mãe faz. melhor" (P8). Além disso, também houve destaque às intensas demandas do emprego do pai, em muitas famílias, conforme evidenciado pelas mães: "Penso assim: Puxa vida, ele trabalhou, né? Acordou cedo'. Daí eu vou. Eu me sinto na obrigação [de cuidar do bebê e fazer as atividades domésticas]" (M6); e pelos pais: "Meu tempo disponível tá muito curto. É mais no domingo [o tempo disponível], e no domingo eu tenho um esgotamento fisico tremendo" (P5).

Em contrapartida, os aspectos financeiros, em muitas famílias, estavam sob responsabilidade predominantemente paterna, como destacado pelas mães: "Pra ele é uma preocupação, no sentido do sustento financeiro, né? É mais uma pessoa na família" (M3); e pelos pais: "Eu assumi todas as despesas" (P9). Ademais, em muitas famílias também se constatou que o orçamento familiar era derivado exclusivamente do salário do pai, já que a mãe era dona de casa, ou mesmo havia saído do emprego em decorrência da gravidez ou do nascimento do bebê: "Trabalhei bastante tempo. Até um pouco antes do [filho] nascer. E então a gente dividia as tarefas. Eu achava legal. Só que agora en fico o dia inteiro em casa" (M6); "Ela sempre teve o dinheiro dela, sempre trabalhou. De repente, com a gravidez, ela perdeu o emprego e isso tá deixando ela insegura" (P7).

$\mathrm{Na}$ maioria das famílias foram identificados relatos de insatisfação quanto à divisão de tarefas e responsabilidades na rotina de cuidados e nas atividades domésticas, sobretudo por parte da mãe: “Eu que mudo, en que dou mamá, en que faço dormir, en que dou banho. Então, eu faço tudo. Mas eu não gosto de fazer, me sinto cansada disso" (M7). Além disso, embora os pais também tenham referido que a divisão de tarefas e responsabilidades parecia insuficiente, ainda assim eles não o faziam: "Acho que não [que a mãe não está satisfeita com a divisão de tarefas e responsabilidades]. Se estivesse satisfeita, não estaria desse jeito. Eu não consegui definir ainda o que é o satisfeito dela [i.e., uma divisão que seria considerada satisfatória pela mãe]" (P9).

Em algumas famílias, os relatos sugeriram ora satisfação, ora insatisfação quanto à divisão de tarefas e responsabilidades, tal como exemplificado por meio das falas da seguinte participante: "O que me agrada, na verdade, é saber que eu posso contar com outra pessoa. [O pai] ajuda, eu gosto" (M2); ao mesmo tempo, essa mesma mãe também referiu: "Tô faz̧endo tudo no momento. E isso é muito chato. Tem que cuidar da roupinha, de... tem parte que é chata" (M2). Em apenas uma família, os relatos maternos evidenciaram satisfação quanto à divisão de tarefas e responsabilidades referentes à rotina de cuidados e às atividades domésticas: "Eu gosto [da divisão de tarefas e responsabilidades]. Me sinto satisfeita” (M3).

\section{Apoio versus Depreciação Coparental}

Essa categoria diz respeito ao quanto cada genitor apoia e afirma a competência do outro, reconhecendo e respeitando suas contribuições, ou ainda ao quanto deprecia e hostiliza o parceiro. Os resultados revelaram relatos sobre apoio coparental em algumas famílias. Assim, vale destacar que as falas maternas e paternas foram tanto no sentido de como os participantes percebiam o cônjuge: "Ele é muito bom pai. Isso en também digo pra ele. Eu confio nele. Eu me sinto segura" (M2); "Ela é carinhosa. Ela tava passando por uma fase de depressão, né? Mas que é uma coisa que pode acontecer com qualquer pessoa. Mas o amor, inato dela, tava ali" (P3); quanto no sentido de como consideravam que o cônjuge os percebia: "Acho que ele [pai] me vê como uma boa mãe, ele sempre fala" (M3); "Ela sempre elogiou muito minha postura como pal" (P2).

Por outro lado, a depreciação coparental também se destacou em algumas famílias. Esse aspecto foi revelado nas falas maternas: "Deixar ela [filha] com ele [pai], é o mais difícil. Se tem alguém que atrapalha? $A i$, às vezzes o [pai]" (M1); bem como nas falas paternas: "Não confio na [mãe] pra cuidar da [filha], sabe? Se ela disser: 'Ah, vou-me embora, não quero mais [o casamento]', sabe? Eu vou fazer de tudo pra tirar a [filha] dela, tu entendeu? Eu vou aonde tiver que ir" (P4).

Salienta-se que em muitas famílias se constatou a coexistência de relatos de apoio e de depreciação coparental, os quais pareceram permeados pela depressão pós-parto, com destaque para sintomas como irritabilidade e cansaço. De tal modo, ora as mães apresentavam relatos de apoio: "É um bom pai. É diferente dos que en já vi. Ele é bem diferente" (M5); ora de depreciação coparental: "Às vezes eles começam a pular demais e eu tenho que ralhar com eles. Eu sempre digo: 'eu não tenho dois filhos homens [o bebê e o irmão mais velho], en tenho três, porque quando tu tá com os guris eu tenho que te aquietar também"" (M5). O mesmo foi evidenciado para os pais, que ora apresentavam relatos de apoio: "Eu [era] até 
muito desajeitado com o nenê. Ela me deu total tranquilidade" (P7); ora de depreciação coparental: "Tem momentos em que ela [mãe] tá realmente cansada. Ultimamente ela tá muito impaciente, até. Qualquer coisa assim é motivo de ela ter um estresse, né? Coisinhas pequenas, ela fica muito irritada. Eu sinto uma certa imaturidade [dela] como mãe" (P7).

\section{Gerenciamento das Interacões Familiares}

Essa categoria se refere ao modo como os pais interagem e se comunicam, sendo constituída por aspectos referentes ao envolvimento triádico e à comunicação familiar. Em uma família, constatou-se que as interações triádicas ocorriam em momentos de brincadeiras: "A gente brinca nós três juntos, a gente senta na cama e a gente fica um tempão brincando" (M9). Também uma família mencionou interações triádicas durante os cuidados ao bebê, em que o pai parecia assumir o papel de liderança, no sentido de direcionar os comportamentos maternos, provocando desconforto à mãe: "Eu ia dar mamá. Ele [dizia] assim: 'deixa que en don'. Porque en tava irritada, nervosa, eu sentia tipo uma afronta. Então, não sou capaz de fazer? Daí eu me sentia mal" (M7). Ademais, em algumas famílias, houve relatos maternos sobre dificuldades para interagir: "Eu me esforço, assim, um pouquinho, e tô conseguindo dar um pouco mais de atenção pra eles. Agora eu tô tomando remédio [para depressão], também" (M3).

Outrossim, muitas famílias apresentaram relatos sobre a comunicação, em que se destacaram estratégias negativas de resolução de conflitos, como brigas. Esses aspectos foram evidenciados tanto nas falas maternas: "Quero evitar o atrito, mas às vezes não dá pra segurar" (M8); quanto paternas: "A gente se perdeu muito, né? Eu acredito que ela deve ter notado a depressão, porque ela mudou completamente. Briga por coisas pequenas, coisas bobas, coisas fúteis. Ela mudou bastante" (P10). Somente em um caso, os relatos sugeriram controle dos genitores sobre a forma como se comunicavam na presença do bebê: "Procuramos não elevar a voz quando ela [filha] tá por perto, pra não ter risco" (P2).

\section{Acordo nos Cuidados}

Essa categoria se refere às concordâncias e às discordâncias dos genitores sobre tópicos relativos ao bebê, e envolve cuidados parentais e arranjos de cuidado. No que diz respeito aos cuidados parentais, a maioria das famílias apresentou relatos de discordância. Isso foi evidenciado em falas maternas: " $O$ [filho], às vezes, chora uma coisinha e ele [pai] já pega no colo. Então, esse tipo de coisa en acho que o [filho] vai ficando mesmo manhoso. Por mais que en fosse dizer, 'ai, não pega, não faz!', ele se preocupa, pega o guri. Isso incomoda. Ele cuida muito" (M7); e paternas: " $A$ [mãe] não quer deixar ele cair, né? Eu já dou mais liberdade, assim. Eu sei que ele vai cair. Todas as crianças da minha família vão cair, se machucar, enfim. $A$ [mãe] já não pensa assim" (P8). Em apenas uma família relatos de concordância foram identificados: "A gente briga por várias outras coisas, mas, pela criança, nunca, pela criança, não, pela criança, é tranquilo" (P2).

Não obstante, os relatos sobre os arranjos de cuidado denotaram prioritariamente concordância entre os genitores. Nesse sentido, algumas famílias optaram pelos cuidados maternos ao bebê, ao passo que muitas outras optaram pela creche. Dentre os motivos para escolherem a creche, algumas famílias mencionaram o fato de ambos os genitores terem emprego e não contarem com o auxílio de outras pessoas para o cuidado do filho: "Não tinha outra alternativa, porque não tinha uma vó sem trabalhar [disponível para cuidar do bebê], né? Ou então, uma profissional [babá]. A gente não tem condição ainda” (P2). Em algumas famílias nas quais apenas o pai tinha emprego, a opção pela creche foi em função da preocupação com as condições da mãe para o cuidado, ou mesmo no sentido de evitar a sobrecarga materna, face à depressão: "O ideal seria a [mãe] ficar com ele o dia inteiro, mas eu não sei, na realidade. Isso aí eu não me sinto seguro. Então, deixar o dia inteiro com ela, não sei. [A decisão pela creche foi de] nós dois" (P7). Ressalta-se que, no momento da coleta de dados, muitas famílias ainda não haviam definido o arranjo de cuidado ao bebê quando a mãe precisasse voltar ao emprego, ao final da licença-maternidade.

\section{Discussão}

A análise conjunta dos resultados revelou semelhanças e particularidades entre as famílias, em relação à coparentalidade no contexto de depressão pós-parto. Aspectos referentes à depressão pós-parto pareceram permear, principalmente, relatos sobre apoio versus depreciação coparental e gerenciamento das interações familiares.

Nesse sentido, chamou a atenção o número de famílias cujos relatos denotaram a coexistência de apoio e depreciação, o qual foi maior que o número de famílias que apresentaram unicamente relatos apoiadores ou depreciadores. Referente a esses achados, a literatura sobre coparentalidade tem sugerido que, em um mesmo subsistema coparental, apoio e depreciação podem coexistir (Feinberg, 2003; Schoppe-Sullivan \& Mangelsdorf, 2013). Porém, nas famílias em que 
se constatou a coexistência de apoio e depreciação, aspectos relativos à depressão foram bastante enfatizados nas falas maternas e paternas. Isso porque os sintomas apresentados pelas mães, tais como humor deprimido, fadiga e irritabilidade aumentada, foram mencionados ora como algo a ser compreendido, ora como algo difícil de tolerar na relação coparental, e que, portanto, transformava-se em alvo de crítica e frustração por parte de ambos os genitores.

Esses achados corroboram a literatura (Feinberg, 2003), ao indicar que os sintomas de depressão pareceram fragilizar a relação coparental, visto que a depreciação coparental se associa a um clima emocional negativo, que pode afetar o desenvolvimento de todos os membros da família. Nessa direção, a saúde mental dos genitores costuma se relacionar à coparentalidade, de modo que, em casos de depressão, a tendência é de dificuldades na expressão de apoio (Cabrera et al., 2009; Williams, 2018), como sugerem os achados do presente estudo. Tais dificuldades na expressão de apoio resultam no aumento da probabilidade de ocorrência de conflitos entre os genitores (Favez et al., 2016). Logo, a depressão tende a impactar o padrão de funcionamento do sistema como um todo, pois interfere tanto nos sentimentos maternos, quanto nas relações dos membros da família (Piccinini et al., 2014; Tissot et al., 2016).

Sobre o gerenciamento das interações familiares, em muitos casos do presente estudo, constatou-se relatos sobre interações triádicas, mesmo que em algumas famílias esses relatos denotassem dificuldades da mãe para interagir. Nesse sentido, destaca-se que o nascimento de um filho gera modificações nos processos psíquicos internos e nos comportamentos dos membros da família (Minuchin, 1982). Assim, quando em adição a esse momento se tem o diagnóstico de depressão, a sobrecarga gerada tende a fragilizar ainda mais a mãe para os relacionamentos interpessoais, bem como a torná-la mais irritadiça (Brockington, 2004; Frizzo et al., 2011a). No presente estudo, esses aspectos também podem ter se associado à escassez de relatos sobre interações triádicas em momentos de descontração, visto que apenas uma família mencionou a ocorrência de brincadeiras que envolvessem, conjuntamente, mãe -pai-bebê. Tais achados corroboram a literatura, pois é recorrente que aconteçam menos interações positivas e mais interações negativas, quando um dos genitores está com depressão (McDaniel, 2016).

Ademais, em uma família se evidenciou a tendência do pai assumir o papel de liderança nas interações triádicas durante os cuidados ao bebê. Sobre esse resultado, é possível que a tentativa do pai de guiar ou liderar as interações triádicas esteja ligada à sua percepção da fragilidade materna, pela depressão pós-parto. Diferentemente, em estudos com mães sem depressão pós-parto, constatou-se que a mulher costumava guiar ou liderar as interações triádicas envolvendo bebês, ao passo que o homem tendia a se comportar conforme as orientações fornecidas pela esposa (Schmidt et al., 2017; Van Egeren, 2004).

No que diz respeito à comunicação na família, identificou-se que muitos participantes pareciam se valer de estratégias negativas de resolução de conflitos. Esse achado corrobora a literatura, pois características individuais, como sintomas depressivos, têm sido identificadas como fatores de risco para dinâmicas coparentais negativas, incluindo brigas entre os genitores (Pinto, 2014). Ademais, esse achado pode ser interpretado com base na perspectiva de que pessoas deprimidas tendem a apresentar maiores dificuldades para entender e explicar causas e consequências de conflitos, o que associado a sintomas de irritabilidade e desvalia costuma prejudicar relações interpessoais (Cummings \& Davies, 1994; Frizzo et al., 2011b).

Embora a comunicação de boa qualidade favoreça a resolução de conflitos coparentais (Augustin \& Frizzo, 2015) e a administração das dificuldades inerentes à rotina familiar (Pasinato \& Mosmann, 2016), ela tende a estar abalada no contexto de depressão pós-parto, justamente quando se faz tão necessária (Cooper \& Murray, 1995; Frizzo et al., 2011b). Dessa forma, é possível que fragilidades na comunicação entre os genitores, potencialmente em função da depressão pós-parto, tenham se relacionado aos relatos sobre estratégias negativas de resolução de conflitos em muitas famílias no presente estudo.

No que se refere ao acordo nos cuidados, os resultados revelaram discordâncias sobre cuidados parentais para a maioria dos participantes, com destaque a expectativas de comportamento, disciplina e necessidades emocionais do bebê. Dado que as atitudes dos genitores são em grande parte baseadas em suas vivências nas famílias de origem, é esperado que discordâncias venham a ocorrer (Feinberg, 2003), notadamente nos primeiros meses de vida do bebê, por se tratar de um período de adaptação aos novos papéis e à relação triádica (Cowan \& Cowan, 2016). De tal forma, esses resultados não pareceram se relacionar especificamente ao contexto de depressão pós-parto, pois discordâncias podem estar presentes em qualquer família com um bebê pequeno. 
Por outro lado, um bom nível de acordo entre os genitores costuma facilitar os ajustamentos necessários após o nascimento do bebê (Don et al., 2013). Entretanto, quando a comunicação não é favorável, a realização de acordos tende a ser mais complexa (Augustin \& Frizzo, 2015), sendo que esses aspectos podem ter permeado as falas das mães e dos pais no presente estudo. Adicionalmente, os sintomas de depressão estão associados a uma maior dificuldade para realizar acordos, relacionar-se de modo cooperativo e tolerar a frustração (McDaniel, 2016), o que parece ter ocorrido na amostra investigada, no que tange aos cuidados parentais.

Por outro lado, é interessante notar que os relatos sobre o arranjo de cuidado denotaram concordância entre os genitores na maioria dos casos do presente estudo. Uma possível explicação seria a organização prévia das famílias em termos do ingresso dos genitores no mercado de trabalho. Assim, talvez antes mesmo do nascimento do bebê e do surgimento dos sintomas de depressão pós-parto, o arranjo de cuidado já havia sido definido pelos genitores, diferentemente dos cuidados parentais, os quais tendem a ser negociados frente às novas demandas que surgem no cotidiano familiar.

Um aspecto que chamou a atenção foi a escolha pela creche mesmo em algumas famílias nas quais apenas o pai tinha emprego e a mãe era dona de casa, o que foi justificado em função das condições maternas para o cuidado, ou mesmo para evitar a sobrecarga da mulher, devido à depressão. Mães com depressão tendem a sentir falta de energia ou motivação (Schmidt et al., 2005), bem como a perder interesse por atividades anteriormente consideradas prazerosas, como as que envolvem interações com outras pessoas (Piccinini et al., 2014; Sit \& Wisner, 2009), conforme reportado no presente estudo. Esses aspectos podem dificultar a realização dos cuidados ao bebê e, por conseguinte, podem ter se associado à escolha pela creche nessas famílias em que apenas o pai tinha emprego. Adicionalmente, em casos de depressão, também é relativamente comum o declínio da responsividade materna (Silva et al., 2016) e, até mesmo, o medo de que a mãe fique sozinha com o bebê (Schmidt et al., 2005), o que também foi referido no presente estudo. Assim, é possível que recursos comunitários - incluindo instituições educacionais, como a creche - consistam em apoio social às famílias, de modo a favorecer o ajustamento coparental frente a situações estressoras, como as que envolvem a depressão pós-parto.
No que diz respeito à divisão de trabalho parental, os resultados revelaram que a rotina de cuidados ao bebê e de atividades domésticas estava mais sob responsabilidade materna, enquanto os aspectos financeiros mais sob responsabilidade paterna. Esses resultados não pareceram consistir em uma particularidade da coparentalidade no contexto de depressão pós-parto, pois estudos que investigaram contextos de desenvolvimento normativo após o nascimento do bebê, também evidenciaram a tendência de distribuição de tarefas e responsabilidades pautadas em papéis mais tradicionais de gênero (Block, 2016; McClain \& Brown, 2016).

Por outro lado, segundo Goldberg e Perry-Jenkins (2004), o fato de as mães assumirem grande parte da rotina de cuidados ao bebê e de atividades domésticas - tal como evidenciado no presente estudo - pode contribuir para maiores índices de depressão nas mulheres. No caso das mães do presente estudo, muitas não estavam trabalhando fora, seja em função da licença-maternidade, ou mesmo por não terem emprego, o que proporcionava maior disponibilidade de tempo para a interação da díade mãe-bebê, consequentemente acarretando maior sobrecarga materna (Martins et al., 2016; Schmidt et al., 2017). Além disso, algumas dessas participantes deixaram o emprego em decorrência da gravidez ou do nascimento do bebê. Ao se afastar do emprego, a mulher costuma se afastar também das relações sociais (com perda de interações com colegas, por exemplo), o que se constitui em fator de risco à depressão (Murray, 2015), de modo que esse aspecto também pode ter permeado a vivência das participantes do presente estudo.

Não obstante, para Feinberg (2003), o principal ponto a ser considerado na divisão de trabalho parental é a satisfação com a maneira de negociar a distribuição de tarefas e responsabilidades, bem como com os resultados dessa distribuição. Nessa direção, quando as expectativas da mãe e do pai quanto à contribuição do outro genitor são violadas, há mais chances de ocorrência de depressão (Block, 2016; Feinberg, 2003; Van Egeren, 2004). Além disso, mães com depressão podem ter uma representação negativa de si mesmas, bem como das relações familiares, o que costuma refletir na insatisfação com a divisão de trabalho parental (Piccinini et al., 2014). Por outro lado, como na grande maioria das famílias participantes do presente estudo, a rotina de cuidados ao bebê e de atividades domésticas estava sob responsabilidade predominantemente materna, é possível que não se trate apenas de uma impressão negativa dessas mulheres, visto que inclusive 
alguns dos pais destacaram que a divisão de trabalho parental poderia ser mais igualitária.

\section{Considerações Finais}

O presente estudo investigou a coparentalidade no contexto de depressão pós-parto. Os achados revelaram que sintomas de depressão pós-parto (ex., irritabilidade e cansaço) apareceram associados à coparentalidade, principalmente por meio de relatos de pouco apoio e depreciação coparental, bem como de fragilidades na comunicação e no relacionamento da tríade mãe-pai-bebê, o que corrobora a literatura sobre a coparentalidade no contexto de depressão pós-parto. Por outro lado, questões sobre divisão de trabalho parental e acordo nos cuidados ao bebê apareceram em menor grau associadas aos sintomas da depressão pós-parto, o que sugere que as situações vivenciadas pelos participantes, ao menos no que se refere a esses aspectos, refletiram desafios de certa forma esperados em contextos normativos de desenvolvimento familiar.

Sobre as limitações do estudo, salienta-se que alguns genitores, em suas respostas às entrevistas, não referiram todas as categorias e subcategorias analisadas. Isso pode se dever às particularidades das dinâmicas relacionais das famílias, ou mesmo à impossibilidade dessas categorias e subcategorias darem conta da complexidade envolvida na coparentalidade no contexto de depressão pós-parto. Nesse sentido, pesquisas futuras podem utilizar abordagem indutiva para investigar a coparentalidade no contexto de depressão pós-parto. Por outro lado, um dos pontos fortes do presente estudo foi a participação da mãe e do pai, o que contribuiu para a compreensão das peculiaridades das interações triádicas nas famílias investigadas, ao considerar expectativas, comportamentos e sentimentos maternos e paternos sobre a coparentalidade no contexto de depressão pós-parto. Além disso, a amostra era clínica - com avaliação da depressão -, em que o tratamento psicoterápico foi indicado frente ao sofrimento vivenciado pelos participantes.

Sugere-se também que pesquisas futuras investiguem a coparentalidade antes e após o tratamento da depressão pós-parto, para avaliar possíveis mudanças na forma como as figuras parentais coordenam e se apoiam no processo de cuidar do bebê, o que poderá trazer contribuições importantes à área. Face aos resultados do presente estudo, ressalta-se a importância de intervenções visando o acompanhamento e o tratamento da depressão pós-parto, com destaque àquelas que não se restrinjam exclusivamente à mãe, mas envolvam também o pai e o bebê. Isso porque situações relacionadas à depressão pós-parto costumam trazer implicações a todos os membros da família. Outrossim, o processo terapêutico deve iniciar tão logo quanto possível, para prevenir consequências mais severas, em nível individual e familiar.

\section{Referências}

American Psychiatric Association (2014). Manual diagnóstico e estatístico de transtornos mentais (DSM-5). Porto Alegre: Artmed.

Augustin, D., \& Frizzo, G. B. (2015). A coparentalidade ao longo do desenvolvimento dos filhos: Estabilidade e mudança no $1^{\circ}$ e $6^{\circ}$ ano de vida. Interação em Psicologia, 19, 13-24. doi: 10.5380/psi.v19i1.29239

Beck, A. T., \& Steer, R. A. (1993). Beck depression inventory: Manual. San Antonio: Psychological Corporation.

Block, J. (2016). Relationship satisfaction and coparenting over the transition to parenthood: Depression, division of labor, and child temperament as moderators (Masters' thesis). Recuperado de http://digitalcommons.odu.edu/ cgi $/$ viewcontent.cgi?article $=1019 \&$ context $=$ psych ology_etds

Brockington, I. (2004). Postpartum psychiatric disorders. Lancet, 24, 303-310. doi: 10.1016/ S0140-6736(03)15390-1

Cabrera, N. J., Shannon, J. D., \& La Taillade, J. J. (2009). Predictors of coparenting in Mexican American families and links to parenting and child social emotional development. Infant Mental Health Journal, 30, 523-548. doi: 10.1002/imhj.20227

Cooper, P. J., \& Murray, L. (1995). Course and recurrence of postnatal depression: Evidence for the specificity of the diagnostic concept. British Journal of Psychiatry, 166, 191-195. doi: 10.1192/ bjp.166.2.191

Cowan, P. A., \& Cowan, C. P. (2016). Transições familiares normativas, qualidade da relação do casal e desenvolvimento sadio dos filhos. Em F. Walsh (Eds.), Processos normativos da família: Diversidade e complexidade (pp. 428-451). Porto Alegre: Artmed.

Cummings, M. E., \& Davies, P. T. (1994). Maternal depression and child development. Journal of Child 
Psychology and Psychiatry, 35, 73-112. doi: 10.1111/ j.1469-7610.1994.tb01133.x

Cunha, J. A. (2001). Escalas Beck. São Paulo: Casa do Psicólogo.

Don, B. P., Biehle, S. N., \& Mickelson, K. D. (2013). Feeling like part of a team: Perceived parenting agreement among first-time parents. Journal of Social and Personal Relationships, 30, 1121-37. doi: 10.1177/0265407513483105

Favez, N., Tissot, H., Frascarolo, F., Stiefel, F., \& Despland, J. N. (2016). Sense of competence and beliefs about parental roles in mothers and fathers as predictors of coparenting and child engagement in mother-father-infant triadic interactions. Infant and Child Development, 25, 283-301. doi: 10.1002/ icd.1934

Feinberg, M. E. (2003). The internal structure and ecological context of coparenting: A framework for research and intervention. Parenting: Science and Practice, 3, 95-131. doi: 10.1207/ S15327922PAR0302_01

Frizzo, G. B., Prado, L. C., Linares, J. L., \& Piccinini, C. A. (2011a). Aspectos relacionais da depressão: O conceito de "honorável fachada" em dois casos clínicos. Psicologia Clinica, 23, 133-155. doi: 10.1590/ S0103-56652011000100009

Frizzo, G. B., Prado, L. C., Linares, J. L., \& Piccinini, C. A. (2010). Depressão pós-parto: Evidências a partir de dois casos clínicos. Psicologia: Reflexão e Crítica, 23, 46-55. doi: 10.1590/S0102-79722010000100007

Frizzo, G. B., Silva, I. M., Piccinini, C. A., \& Lopes, R. C. (2011b). Comunicação conjugal durante a transição para parentalidade no contexto de depressão pós -parto. Psicologia, 25(2),39-60. Recuperado dehttp:/ / www.scielo.mec.pt/scielo.php?script=sci_arttext\& pid $=$ S0874-20492011000200003

GIDEP/NUDIF (2003). Entrevista diagnóstica. Instrumento não publicado, Instituto de Psicologia, Universidade Federal do Rio Grande do Sul, Porto Alegre, Brasil.

Goldberg, A. E., \& Perry-Jenkins, M. (2004). Division of labor and working-class women's well-being across the transition to parenthood. Journal of Family Psychology, 18, 225-236. doi: 10.1037/0893-3200.18.1.225
Laville, C., \& Dionne, J. (1999). A construção do saber: Manual de metodologia da pesquisa em ciências humanas. Porto Alegre: Artmed.

Maršanić, V. B., \& Kušmić, E. (2013). Coparenting within the family system: Review of literature. Collegium Antropologicum, 37(4), 1379-1384. Recuperado de https://www.ncbi.nlm.nih.gov/ pubmed/24611362

Martins, G. D., Leal, C. L., Schmidt, B., \& Piccinini, C. A. (2016). Maternidade e trabalho: Experiência de mulheres com carreiras profissionais consolidadas. Manuscrito submetido.

McClain, L., \& Brown, S. L. (2016). The roles of fathers' involvement and coparenting in relationship quality among cohabiting and married parents. Sex Roles, 76, 334-345. doi: 10.1007/s11199-016-0612-3

McDaniel, B. T. (2016). Understanding stability and change in daily coparenting: Predictors and outcomes in families with young children (Doctoral dissertation). Recuperado de https://etda.libraries.psu.edu/catalog/ d217qp48j

Minuchin, S. (1982). Familias: Funcionamento e tratamento. Porto Alegre: Artes Médicas.

Murray, M. (2015). Back to work? Childcare negotiations and intensive mothering in Santiago de Chile. Journal of Family Issues, 36, 1171-1191. doi: /10.1177/0192513X14533543

Pasinato, L., \& Mosmann, C. P. (2016). Transição para a parentalidade e a coparentalidade: Casais que os filhos ingressaram na escola ao término da licença -maternidade. Avances en Psicología Latino-Americana, 34, 129-142. doi: 10.12804/apl34.1.2016.09

Piccinini, C. A., Frizzo, G. B., Brys, I., \& Lopes, R. C. S. (2014). Parenthood in the context of maternal depression at the end of the infant's first year of life. Estudos de Psicologia, 31, 203-214. doi: 10.1590/0103-166X2014000200006

Piccinini, C. A., Silva, M. D., Gonçalves, T. R., Lopes, R. C., \& Tudge, J. (2012). Envolvimento paterno aos três meses de vida do bebê. Psicologia: Teoria e Pesquisa, 28, 303-314. doi: 10.1590/ s0102-37722012000300006

Piccinini, C. A., Prado, L., Lopes, R. C., Schwengber, D., Alfaya, C., Frizzo, G. B., . . \& Silva, M. (2003). O impacto da psicoterapia para a depressão materna e para a interação pais-bebê: Estudo longitudinal 
do nascimento ao segundo ano de vida do bebê. Projeto de pesquisa não publicado, Instituto de Psicologia, Universidade Federal do Rio Grande do Sul, Porto Alegre, Brasil.

Pinto, T. M. (2014). Coparenting in fathers during the transition to parenthood (Doctoral dissertation). Recuperado de http://repositorium.sdum.uminho.pt/ handle/1822/32815

Schmidt, B., Arenhart, V. S., Lopes, R. C., \& Piccinini, C. A. (2017). Coparentalidade aos três meses de vida do bebê. Manuscrito submetido.

Schmidt, E. B., Piccoloto, N. M., \& Müller, M. C. (2005). Depressão pós-parto: Fatores de risco e repercussões no desenvolvimento infantil. Psico-USF, 10(1), 61-68. Recuperado de http://www.scielo.br/pdf/ pusf/v10n1/v10n1a08.pdf

Schoppe-Sullivan, S. J., \& Mangelsdorf, S. C. (2013). Parent characteristics and early coparenting behavior at the transition to parenthood. Social Development, 22, 363-383. doi: 10.1111/sode.12014

Schoppe-Sullivan, S. J., Yavorsky, J. E., Bartholomew, M. K., Sullivan, J. M., Lee, M. A., Kamp Dush, C. M., \& Glassman, M. (2016). Doing gender online: New mothers' psychological characteristics, Facebook use, and depressive symptoms. Sex Roles, 76, 276-289. doi: 10.1007/s11199-016-0640-z

Silva, A. P., Pizeta, F. A., \& Loureiro, S. R. (2016). Stressors and perceived social support in women/ mothers with depression. Psico-USF, 21, 583-594. doi: 10.1590/1413-82712016210312
Sit, D. K., \& Wisner, K. L. (2009). The identification of postpartum depression. Clinical Obstetrics and Gynecology, 52, 456-468. doi: 10.1097/ GRF.0b013e3181b5a57c

Theme Filha, M. M., Ayers, S., Gama, S. G., \& Leal, M. C. (2016). Factors associated with postpartum depressive symptomatology in Brazil: The birth in Brazil national research study, 2011/2012. Journal of Affective Disorders, 194, 159-167. doi: 10.1016/j. jad.2016.01.020

Tissot, H., Favez, N., Frascarolo, F., \& Despland, J. N. (2016). Coparenting behaviors as mediators between postpartum parental depressive symptoms and toddler's symptoms. Frontiers in Psychology, 7. doi: 10.3389/fpsyg.2016.01912

Van Egeren, L. A. (2004). The development of the coparenting relationship over the transition to parenthood. Infant Mental Health Journal, 25, 453-477. doi: 10.1002/imhj.20019

Verza,F., Sattler,M. K.,\&Strey,M.N. (2015).Mãe, mulher e chefe de família: Perspectivas de gênero na terapia familiar. Pensando Famílias, 19(1), 46-60. Recuperado de http://pepsic.bvsalud.org/scielo.php?script=sci_arttext\&pid=S1679-494X2015000100005

Williams, D. T. (2018). Parental depression and cooperative coparenting: A longitudinal and dyadic approach. Family Relations, 67, 253-269. doi: $10.1111 /$ fare. 12308

Recebido em: 21/01/2018 Reformulado em: 30/05/2018

Aprovado em: 24/06/2018 
Sobre os autores:

Giana Bitencourt Frizzo é psicóloga, especialista em Terapia de Casal e Família, mestre e doutora em Psicologia e professora da Universidade Federal do Rio Grande do Sul, atuando na graduação, especialização, mestrado e doutorado em Psicologia.

ORCID: 0000-0001-8106-4441.

E-mail: gifrizzo@gmail.com

Beatriz Schmidt é psicóloga, especialista em Saúde da Família, mestre e doutora em Psicologia e pós-doutoranda em Psicologia, no Núcleo de Infância e Família da Universidade Federal do Rio Grande do Sul.

ORCID: 0000-0003-2907-2297.

E-mail: psi.beatriz@gmail.com

Vanessa de Vargas é estudante do curso de Graduação em Psicologia da Universidade Federal do Rio Grande do Sul. ORCID: 0000-0003-1786-6604.

E-mail:vargasdevanessa@gmail.com

Cesar Augusto Piccinini é psicólogo, mestre e doutor em Psicologia, professor titular da Universidade Federal do Rio Grande do Sul, atuando na graduação, especialização, mestrado e doutorado em Psicologia e coordenador do Núcleo de Infância e Família da Universidade Federal do Rio Grande do Sul.

ORCID: 0000-0002-4313-3247.

E-mail:piccinini@portoweb.com.br

Contato com os autores:

Rua Ramiro Barcelos, 2777, Sala 314, Bairro Santa Cecília

Porto Alegre-RS, Brasil 